not military calculations. Will a more bellicose president $(\mathrm{Mr}$ Reagan) also be more isolationist? Would President Carter, if reelected, be able to balance his apparently incorrigible unawareness of the European consequences of his domestic pronouncements (such as that about Directive 59) with the flexible and imaginative view of Sait II, Salt III and the other matters at the root of European security to keep the confidence of his NATO allies? Time, no doubt, will tell.

Until that issue is resolved, there are bound to be hankerings in Western Europe after the position adopted by the French a quarter of a century ago, when the Gaullist doctrine of independence was evolving. The French position is quite clear, and has been consistent from the start. In the last resort, the argument goes, even the most solemn guarantees are likely to be abrogated. It makes no sense to think that the people of the United States will knowingly sacrifice themselves for the sake of France. On the other hand, France can safeguard its own future by acquiring an independent nuclear force able to inflict damage on potential adversaries that is more or less proportional to its own potential value as a prize. The British case for the retention of an independent deterrent, much rehearsed when the British government decided three weeks ago to adopt the Trident system of nuclear submarines as its next-generation nuclear deterrent, is subtly different. The objective, that argument runs, is to influence the perceptions not of allies but of adversaries: if it should be thought by others - however mistakenly - that the
United States might, in a tight corner, leave Europe to its own devices, the result might be a conflict that would otherwise be deterred. The West German government, denied both these options by its solemn declaration within the Western European Union that it would never become a nuclear power, is understandably (and rightly) more concerned with the threat from Soviet medium-range missiles across the Eastern frontier and would like faster progress with Salt III.

What, in these uncertain circumstances, is to be done? The conventional advice is to wait until after the American election (and then perhaps to wait until a new Administration is installed). That is a counsel of defeat. It is in the best interests of NATO, but would also serve the good cause of diminishing the risk of strategic conflict, if the three principal European states were to use the forthcoming period of uncertainty to decide among themselves what they want for European security. The British and French justifications of their independent nuclear forces are not so different that they could not be reconciled, while both are consistent with a NATO agreement with the Warsaw Pact on medium-range missiles (Salt 11I). Conventionally, again, it is supposed that an Anglo-French deterrent is unthinkable and that Salt III must wait on Salt II coming out of limbo (which in turn must wait on Afghanistan and, again, the election). But this is not a time for making decisions that must of necessity occupy most of the 1980s. President Carter's announcement of Directive 59, domestically, is an opportunity to begin that process.

\title{
What price the price of crude petroleum?
}

The recession in the industrialized countries of the West is now also beginning to hurt the oil-producing states. In the past few weeks, production in many OPEC states has declined as consumption in many industrialized states has stagnated or even fallen marginally. Some producers are now trimming back the premiuns they have been in the habit of adding to the prices on which they have been settling at the periodic OPEC price fixings, with the result that the prices charged for refined products, especially petrol or gasoline, have themselves fallen by a per cent or so. Meanwhile, the Rotterdam spot market (which is not physically in Rotterdam but rather is the name for a system by which oil traders sell tankerfuls of oil to each other while the ships are still at sea) has seen the price of crude oil fall back and the volume offered for sale by the oil-producing states shrink to a trickle. Understandably, if prices are falling, the oil producers prefer to leave their petroleum in the ground. Only some of the oil producers, Iran most conspicuously, will be embarrassed if, for a time, oil revenues noticeably shrink. But the emerging slump in the demand for oil differs in many important ways from previous occasions in the recent past, 1976 for example, when there seemed to be a surplus of crude oil. It is also an opportunity for the oilconsuming states of the industrialized West to put their own pricing policies for oil in order.

There is some evidence that the present slackening of demand for oil reflects not merely the economic recession in the West but the beginning of an underlying trend towards reduced oil consumption. That this should be happening is merely a sign that increased prices bring lower consumption, the sort of thing that Adam Smith was saying 200 years ago. The only surprise is that it has taken seven years, since the first dramatic increases of the price of oil in the autumn of 1973, for consumers to make arrangements to manage with less. Ironically, in this the first stage of the recession, high interest rates will be a brake on the pace at which new capital developments might help to accelerate the conversion of industrial plant and commercial buildings to more efficient ways of using energy. It may be some small comfort for everybody concerned that, if this recession follows the standard pattern, there will come a time when interest rates are low again. On present form, however, even if present trends persist, it will be a decade or so before the industrialized West's dependence on imported OPEC oil has lessened to the point at which the consumers will be able to look the suppliers in the eye and argue about the price of oil.

In the meantime, there are other steps that could and should be taken, the chief of which is to bring about a greater of harmony between the oil pricing policies of the consumer states. For governments appear still be divided on the objectives of their oil pricing policy: they see higher prices as a means of encouraging conservation, but they differ in the degree to which they wish to protect their electors from reality. The worst offender is the United States, where Congress has stolidly declined to let the Administration take steps to let the price of oil rise towards the international price of crude. (Is that another issue that will be more easily decided when the presidential election has been run?) One result is that the pressures towards conservation are not as strong as they might have been. Another is that energy-intensive industries in the United States are blessed with a commercial advantage over their competitors elsewhere which is widely considered to be unfair. In the past few weeks, there have been rumblings from the European chemical industry that European governments will not be able indefinitely to ignore. Yet they appear to be unwilling to follow the sensible course of harmonizing their systems for taxing oil so as to ensure that, at least within Europe, nobody has an unfair advantage. The European Commission's proposals to this end were given short shrift earlier this year. In Europe, perhaps the worst offender is the British government, which rigidly follows OPEC prices in trading North Sea oil without apparently appreciating the strategic benefits that would flow from a slightly lower price.

Further ahead, the overriding need is for a mechanism resembling a free market that would serve as a means of fixing a realistic price for oil and, ultimately, for other fuels. The notion that oil importers that are also oil producers (chiefly the United Kingdom and the United States) might deliberately use part of their production to increase the volume of crude oil traded on the Rotterdam market (see Nature, 3 July) could not fail to have some influence on future OPEC prices. The attempts now being made to organize a future market in crude petroleum, great though the technical difficulties may be, could be an influence of the same kind. The trouble, as ahways, is that Western oil producers are unwilling to sacrifice any part of their security of supply for the benefits (to them as well as others) of lower prices. 